\title{
Enhancing Supply Chain Capabilities in an ETO Context Through "Lean and Learn"
}

\author{
Jenny Bäckstrand \\ Division of Supply Chain \& Operations Management, School of Engineering, \\ Jönköping University, Sweden. \\ E-mail: jenny.backstrand@ju.se (Corresponding Author) \\ Daryl John Powell \\ SINTEF Manufacturing AS, Raufoss, Norway; and \\ Norwegian University of Science and Technology, Trondheim, Norway \\ Email: Daryl.Powell@sintef.no
}

\begin{abstract}
In the operations management literature, organizational learning has recently begun to emerge as an important missing link to successful lean transformations. As such, drawing on insights from two case companies in the engineer to order (ETO) industry, we frame the successful enhancement of supply chain capabilities through a lens we call "Lean and Learn". Continuous improvement without learning is not lean thinking. Thus, lean thinking and practice is, in essence, a process of learning; where problems are identified and solutions are created, analysed, selected, and implemented; resulting not only in improved performance but also in improved capability. Since the ETO industry exhibits project-based production, there seems to be natural barriers and resistance to continuous improvement and learning. By building on the notion that an organization with an improved capability is an organization that has learned, this study examines the link between supply chain capabilities and organizational learning in an ETO context by combining analytical conceptual reasoning with meta-data collected from action research at two case companies. The study contributes to practice by pointing out how supply chain capabilities can be enhanced in an ETO context, and to academia by identifying and offering new knowledge to start filling the research gap between three specific research areas: ETO supply chains, organizational learning, and lean management.
\end{abstract}

Keywords: organizational learning, lean management, engineer to order, supply chain management, continuous improvement.

\section{INTRODUCTION}

The engineer to order (ETO) supply chain is generally regarded as a supply chain where the customer order penetration point occurs during the design phase of a product. It is primarily associated with large, complex project environments in sectors such as construction and capital goods (Gosling and Naim, 2009) or the shipbuilding industry (Mello and Strandhagen, 2011). However, it is also relevant for make to order (MTO) companies offering customizations (Bäckstrand and Engström, 2017). The development of supply chain management theory and practice in ETO supply chains is still relatively immature when compared with other types of supply chains, for example those that produce high-volume, low-mix products (Mello et al., 2017).

ETO is often seen as a project-based) production system or a one-time event, i.e., a temporary endeavour undertaken to create a unique product. However, quality management mainly relays on processes with repetitive activities. Thus, there are limited studies of continuous improvement from the perspective of a project-based organization such as the ETO supply chain (Backlund and Sundqvist, 2018). The fragmented and temporary nature of ETO supply chains also contributes to the lack of knowledge transfer from one project to another (Jensen, 2017), hence hindering process innovations and organizational learning processes.

Due to the project-based nature of ETO-supply chains, several authors report difficulties with regard to adoption of lean management in these types of organizations (e. g. Irani, 2020; Powell and van der Stoel, 2017). When reduced to a process improvement method and set of tools and techniques for operational excellence, lean implementations often quickly fail and are replaced by the next flavour-of-themonth, operations management fad. Those that succeed with lean realize that behind all the best practices and the different management system that supports their use lies a much deeper, challenge - a cognitive transformation that develops the human potential of everyone to create a culture of accelerated continuous improvement to meet the changing circumstances of today and tomorrow. Learning is at the heart of lean (Ballé et al., 2019b). In fact, organizational learning has recently begun to emerge as the missing link to successful lean transformation (Engström and Käkelä, 2019; Powell and Coughlan, 2020b), regardless of the positioning of the customer order penetration point.

The aim of this study is to contribute to practice by pointing out how, contrary to popular belief, ETO supply chain capabilities can indeed be enhanced by systematic application of lean thinking and practice. We also aim to contribute to academia by identifying and offering new knowledge to start filling the research gap between three research areas: organizational learning, lean management, and ETO supply chains. As such, the purpose of this paper is to provide indications as to how supply chain capabilities in 
an ETO context may be enhanced through applying a phenomenon we coin "Lean and Learn". We adopt the following research question to guide our investigation:

$\boldsymbol{R Q}$ : How can lean thinking and practice be used to enhance supply chain capabilities in Engineer to order (ETO) manufacturing?

Drawing on insights from two case companies in the ETO industry (see e.g. Jonsson Egeman, 2019), we frame the successful enhancement of supply chain capabilities through the "Lean and Learn" lens. Continuous improvement without learning is not lean thinking (Netland and Powell, 2017). Therefore, continuous improvement must in essence be a process of learning; where problems are identified and solutions are created, analysed, selected, and implemented; resulting not only in improved performance but also in improved capability of the firm. Consequently, in this paper, we provide a research framework that can be used for examining the important links between Lean, learning and supply chain capabilities. By building on the notion that an organization with an improved capability is an organization that has learned, this study examines the link between supply chain capabilities and organizational learning in an ETO context by combining analytical conceptual reasoning with meta-data collected from action research at two distinct case companies.

\section{THEORETICAL BACKGROUND}

When theorizing in organizational studies, Hansen and Madsen (2019) present a literature review as a process of finding one's academic family. In finding our family, in this section we present three research areas that provide the theoretical frame for our investigation: ETO supply chains, lean management and organizational learning.

\subsection{ETO Supply Chains}

The ETO supply chain has emerged as a major supply chain structure and is set to become increasingly important as more customised products are demanded across a range of industries (Käkelä and Bäckstrand, 2019). In general, ETO supply chains produce low volumes of a high variety of products and allow customers to demand products which are developed in order to exactly satisfy their needs (Wortmann et al., 1997). ETO supply chains involve multiple companies performing diverse activities during a project, such as design, engineering, procurement, manufacturing, assembly and commissioning, and they are primarily associated with complex project environments in sectors such as heavy equipment (Elfving et al., 2002), construction and capital goods (Gosling and Naim, 2009) and shipbuilding (Mello and Strandhagen, 2011). However, recently it has also been identified that companies within other sectors and a general manufacturing strategy of make to order (MTO) can offer customizations as ETO products (Bäckstrand and Engström, 2017).

ETO supply chain frameworks agree that the production flow is completely driven by actual customer orders with the decoupling point (Hoekstra and Romme, 1992) located at the design stage (see Figure 1). However, several frameworks disagree on the definitions for the design dimension. Some argue that ETO companies modify existing orders while others argue that completely new designs are developed to order. Furthermore, others argue that ETO supply chains only operate in a project environment with project specific demands for one-of-a-kind products (Gosling and Naim, 2009). In order to clarify and differentiate between these dimensions, Wikner and Rudberg (2005) propose a framework with an engineering dimension and production dimension. Regardless of the definition of ETO supply chains, the ability to effectively coordinate cross-business activities is essential to avoid delays, cost overruns and quality problems (Mello et al., 2015).

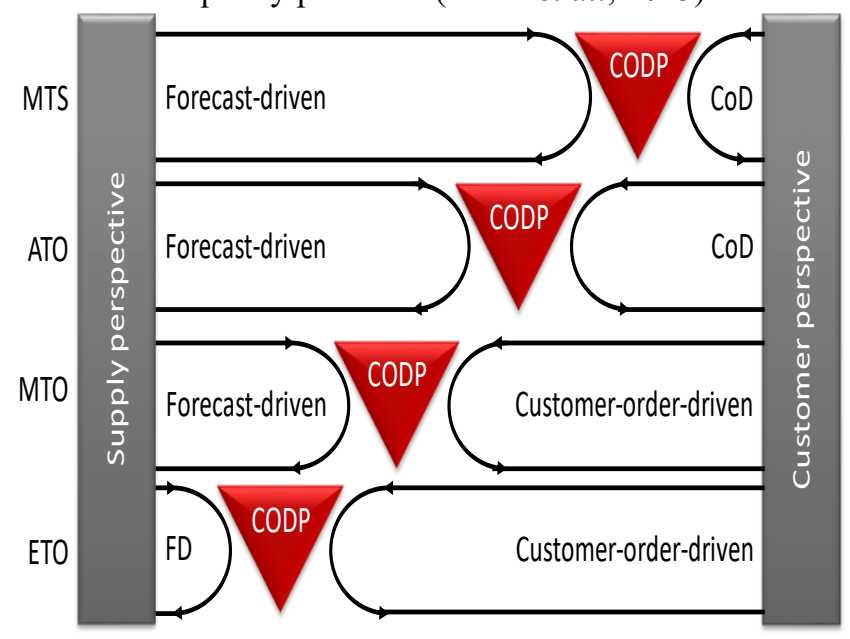

Figure 1 Different positions of the CODP, depending on the supply-demand strategy

Regardless of which CODP strategy a firm might adopt, the ability to effectively coordinate cross-business activities gives companies a competitive advantage. This advantage can be operationalized in supply chain capabilities. These capabilities have historically been defined as quality, cost, and delivery performance (Fine and Hax, 1985; Skinner, 1969; Wheelwright, 1978). Initially, these capabilities were assumed to be trade-offs, but they were later identified as mutually supportive (Ferdows and De Meyer, 1990; Nakane, 1986) or a hybrid (Hallgren et al., 2011).

\subsection{Lean Management}

To improve a firm's supply chain capabilities, some authors within the field of operations management present and promote leagility as a strategic concept that represents a combination of both lean and agile (Naylor et al., 1999). Framed as such, in this respect, lean is assumed to be purely a cost-based strategy that is appropriate in a forecast-driven context upstream of the customer order decoupling point (CODP), whilst agile is the corresponding flexibility-based strategy in a customer-order-driven context downstream of the CODP (see Figure 2).

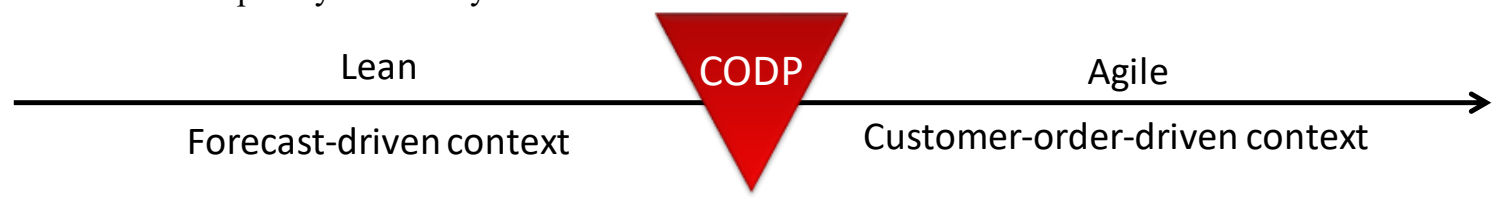

Figure 2 Leagile strategies in relation to the customer order decoupling point (based on Mason-Jones et al. (2000)) 
Consequently, when combined with Figure 2, Figure 1 may lead the reader to envision that a lean strategy is not appropriate in ETO supply chains (despite the fact that not everything is customer-order driven in an ETO supply chain, as even customized products often contain some generic items or standardized processes (Bäckstrand, 2012)). Though this may well be true of a cookie-cutter approach to lean best practice implementation, we argue that when managers see beyond the tools and identify with lean as a cognitive transformation based on discovery and learning (Powell and Coughlan, 2020a), even ETO supply chains can excel by applying lean thinking and practice.

Since it was popularized in the 1990 s by Womack et al. (1990), lean production (or lean management) has become the $21^{\text {st }}$ Century's alternative approach to business management. Lean management promotes continuous improvement, employee engagement, problem-solving and supplier development. For example, Netland and Powell (2017) suggest that lean, cut to the core, is about creating a culture for continuously improving a business or organization. They suggest that any lean transformation regardless of sector or application area - is dependent on what they call the three essential Ls of Lean: Leadership, Learning, and the adoption of a Long-term perspective. Since Liker (2004) highlights that lean involves "becoming a learning organization via constant reflection and continuous improvement", and Ballé et al. (2019a) posit learning as 'the very heart of lean thinking', we suggest that the field of organizational learning may present further insights necessary for successfully enhancing ETO supply chains (Chakraborty and Gonzalez, 2018).

\subsection{Organizational Learning}

Nevis et al. (1995 p.73) define organizational learning as "the capacity or processes within an organization to maintain or improve performance based on experience." They note three learning-related factors which are important for organization success:

1. Well-developed core competencies that serve as launch points for new products and services,

2. An attitude that supports continuous improvement in the business's added value,

3. The ability to fundamentally renew and revitalize.

Furthermore, Crossan et al. (1999) present four key premises that underpin organizational learning:

1. Organizational learning involves a tension between assimilating new learning (exploration) and using what has been learned (exploitation).

2. Organizational learning is multi-level: individual, group, and organization.

3. The three levels of organizational learning are linked by social and psychological processes: intuiting, interpreting, integrating, and institutionalizing (4I's).

4. Cognition affects action (and vice versa).
Organizational learning implies exploitation of the 'already known' to execute tasks in the most efficient way at the same time as the organization explores 'unknowns' (as new areas of knowing) and creates new knowledge to improve and renew the organization or the task performance. This balance between exploitation and exploration builds on the work of March (1991), which presents an understanding of organizational learning and is investigated in the growing research area of ambidexterity (O'Reilly and Tushman, 2004). This balance between exploration and exploitation can also be seen as fundamental to continuous improvement, the continuity of which requiring organizations to strike the balance between exploration and exploitation.

Gustavsson (2007) suggests that contradictions are the very fundament for learning in an activity system and depending on how they are handled, enabling, or hindering, various types of learning in the organizations can be brought about. Knowledge creation is built out of contradictions and on the interaction between the implicit and the explicit knowledge in an organisation (Ellström, 2010; Nonaka, 1994) Developmental oriented learning takes place when the implicit processes are made visible and transparent and results in reflective common agreements. The developmental learning is focusing on the innovative and exploring knowledge. Questioning of routines, trial and change of given ideas, knowledge and activities are essential (Ellström, 2010).

To support knowledge creation processes and thereby stimulate developmental learning in the organization, important knowledge has to be shared within and across functions but also between individuals (Khan and Wisner, 2019; Sánchez et al., 2013). Bechky (2003) shows that the interplay (interaction) between members of different communities (functions) may be painful but also lead to enriched understanding, especially as a tangible object is offered as a mediator in the interaction (Bäckstrand and Engström, 2016). To summarize, the knowledge learned by individuals or teams needs to be captured, stored, and made available for others in an organization for any learning process to be effective.

\subsection{Theoretical Framework}

We suggest that in adopting a focus on both lean and organizational learning, i.e., seeing beyond the isolated implementation of lean best practices in operational excellence tradition, manufacturers can enhance supply chain capabilities, such as the improvement of quality, cost, and delivery performance (see Figure 3). We also suggest that there is a synergy to be realized by formally adopting both lean thinking and organizational learning (indicated with the arrows to and from each construct), as lean tools serve as learning frames for fostering double loop learning, and the reflexive nature of organizational learning strengthens continuous improvement capabilities. 


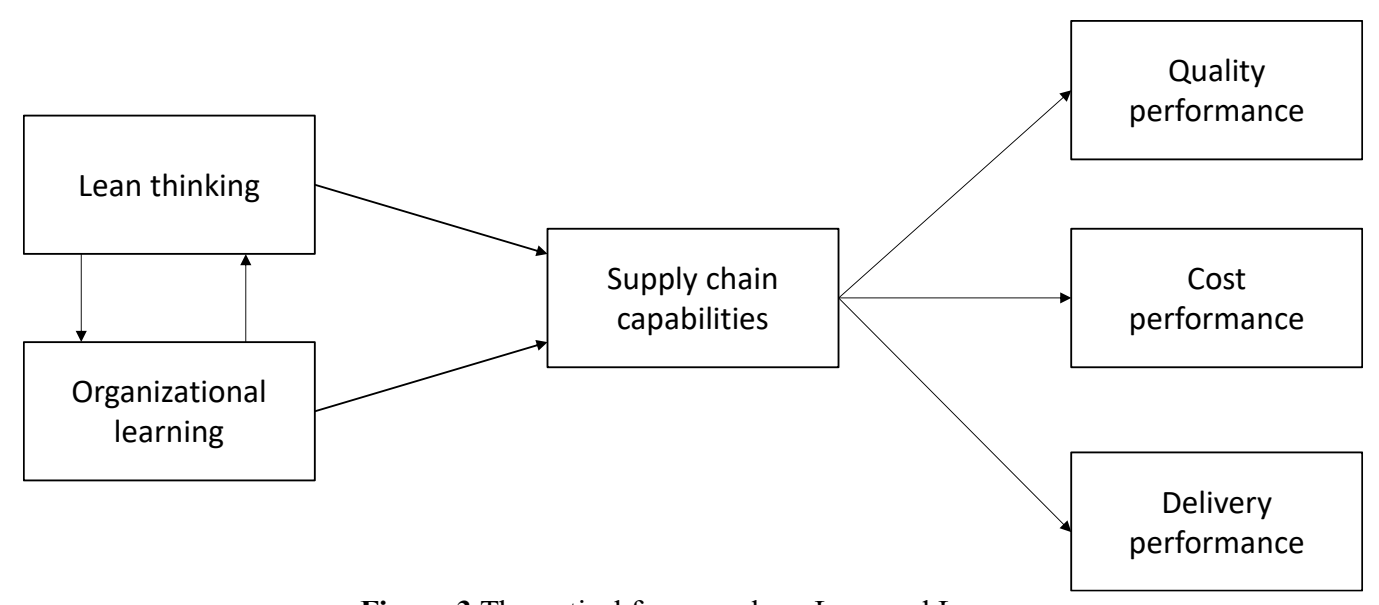

Figure 3 Theoretical framework - «Lean and Learn»

This is particularly relevant for ETO manufacturers which otherwise seem to exhibit natural barriers and resistance to lean and continuous improvement initiatives.

\section{RESEARCH DESIGN}

Our research design is guided by our research question: How can lean thinking and practice be used to enhance supply chain capabilities in Engineer to order (ETO) manufacturing? As such, this research has been designed and carried out in two, main phases: the first adopting an analytical conceptual approach for theory development (Wacker, 1998) that resulted in the development of a theoretical framework, and the second relying on empirical data to check the validity of the theoretical framework. This research therefore has a deductive approach, where the analysis of empirical data has been based on the theoretical framework. First, we presented an interpretative synthesis of the extant literature to find our academic family and design a theoretical framework, see Figure 3.

With the intention to not only accurately describe the phenomenon as such but also to explain how it works, the second phase of the research included empirical illustrations from a selection of ETO companies. Given the practical nature of the problem, and the how-type research question, multiple case study research was selected as the research method, as it promises to provide a deeper understanding of the phenomenon in question (Yin, 2018). A convenience sampling method was taken, and the two cases were selected based on meta-analysis of our own previous action-based research projects. In line with Lacoste and Johnsen (2015) we have thus used 'tacit knowledge' gained through immersion in the field to guide both our conceptual study as well as the selection of cases.

Subsequently, we draw on the retrospective insights of two case studies, both of which represent the Scandinavian maritime sector. Such insights into the practicalities of the problem are based on longitudinal immersion in the field (Wells and Nieuwenhuis, 2017). An overview of the case studies can be seen in Table 1:

Table 1. Overview of Case Studies

\begin{tabular}{|c|c|c|c|c|}
\hline Case & Location & Sector & $\begin{array}{c}\text { Turnover } \\
(\mathbf{2 0 1 7})\end{array}$ & $\begin{array}{c}\text { Number of } \\
\text { employees }\end{array}$ \\
\hline 1 NorCo & Norway & Maritime & $4.0 \mathrm{MNOK}$ & 400 \\
\hline 2 SweCo & Sweden & Maritime & $1.2 \mathrm{MSEK}$ & 220 \\
\hline
\end{tabular}

Cases were selected based on the following criteria:

1) The company should be an ETO manufacturer.

2) The company should exhibit evidence of applying lean thinking and practice both internally and collaboratively with external supply chain partners.

Case descriptions are provided in the following section. These have been constructed based on secondary data, originating from the previous research of both of the authors as well as a third, independent researcher previously engaged in this research. The original data was collected primarily from interviews and direct observation in each of the case companies.

\section{Company 1: NorCo}

NorCo produces subsea equipment to the oil and gas industry and sonar equipment for fishery and naval applications, as well as maritime robotics such as unmanned surface vessels (USVs) and autonomous underwater vehicles (AUV). Though several of the company's products are offthe-shelf, the majority of products are customer-specific, and production is therefore heavily project-based. NorCo began implementing lean in 2014, at the same time as establishing a lean supplier development programme together with a selection of its strategic and preferred suppliers. In 2017, the company was awarded a prestigious lean prize, recognizing the company for having successfully implemented lean in a complex production environment [and supply chain].

The lean implementation began by designing and launching a companywide lean programme based on principles rather than the more popular, traditional approach which entails the idle adoption of tools and techniques. Best practices were however adopted during the lean journey, often as countermeasures in response of learning interventions that occurred during problem-solving and continuous improvement activities. One such example is the adoption of value stream mapping. Where many companies begin the lean implementation process with value stream mapping, NorCo only adopted value stream mapping in response of a need to learn to see the flow of materials and information across its extensive supply chain, engaging several of the strategic and preferred suppliers in the mapping process to promote exploration and subsequent exploitation. What emerged was a learning experience that resulted in quantifiable continuous improvement for all parties (QCD). For example, discovering an opportunity to 
improve the product design led to a subsequent production process improvement at a supplier, and resulted in a $10 \%$ increase in quality performance and $25 \%$ improvement in ontime-delivery from said supplier. Another actor in the supply chain discovered growth potential by offering a completely new product line utilizing the new capacity created by eliminating waste during the lean transformation increasing people productivity onsite by $400 \%$.

One further example was the company's approach to 5S. Rather than blindly adopting $5 \mathrm{~S}$ as a lean best practice, NorCo decided first to work with defining the way in which the company could best benefit from Visual Management engaging frontline personnel in creating a visual management (VM) handbook - designed by the people for the people. This encouraged those involved to explore the solution-space before exploiting any such best practice. The implementation of the VM handbook was supplemented with regular 5S audits (later self-assessments) which also resulted in the continuous improvement of the handbook as well as the VM-standard on-site. The learning that emerged as a result was fundamental to the success of the lean programme, both at NorCo and across external supply chain partners.

A final learning intervention at NorCo was that of lean exemplar site visits - where staff from NorCo were joined by representatives from the supplier network to visit other European exemplary lean organizations - in Sweden, Germany, and the Netherlands. This gave participants opportunities to explore away and exploit at home, also driving the exploration and exploitation elements of continuous improvement. Encouraging improvement at home, one supplier in the NorCo network was able to reduce the cost-of-poor-quality by $30 \%$ via the implementation of A3 management - a learning process built around the PDCA cycle. Another was able to reduce throughput time by $50 \%$ by implementing a simplified Kanban solution that was observed during one of the best practice site visits.

Key to harnessing and redeploying the learning that emerged from the transformation in NorCo was regular Gemba walks across sites with managers, as well as Yokoten, or "horizontal deployment", which refers to the practice of copying good results of improvement in one area to other areas of a firm or supply chain (Miller, 2011). Yokoten also applies more broadly to sharing product design ideas as well as better production practices in general. NorCo also developed an online web platform (using Microsoft SharePoint and Microsoft Teams) for identifying, logging, and sharing the results of continuous improvement activities, as well as sharing an annual, end-of-year lean assessment and status report throughout the network.

\section{Company 2: SweCo ${ }^{1}$}

SweCo manufactures propulsion products for offshore and merchant vessels and oil and gas platforms, such as propellers, water jets, thrusters, and manoeuvring systems. The plant studied here has 220 employees, of which 210 are white-collar workers and 10 are blue-collar workers.

Almost all products produced by the company are ETO products. The production process, excluding assembly, is outsourced to a variety of different suppliers, and focus is subsequently on research and development, customer specific engineering, procurement, and in-house product assembly. This made the company a suitable case company for this study, as the products are customized and engineered to order. The supply chain for SweCo is not temporary but the company does have a one-off project mindset. They also struggled with applying lean thinking to their administrative processes and could not understand or foresee where waste occurred in the business processes.

Following a brief introduction to lean thinking and practice, the company carried out a mapping of its administrative engineering processes and learned to see the extent of waste in such a system - including overproduction (producing too much documentation (Alieva and von Haartman, 2020)), inventory (storing documents in folders and inboxes), waiting (delays waiting for input from other functional representatives), and transportation (moving drawings and documents around - albeit in cyberspace). Eliminating some of this administrative waste allowed SweCo to reduce its lead times up to $50 \%$. Understanding the importance of quality in creating effective design information also had a direct impact upon quality performance, with SweCo observing a 30\% improvement in scrap and rework costs over a period of just 12 months.

\section{DISCUSSION / ANALYSIS}

We frame our discussion around the illustration presented in Figure 4, which shows that to increase customer value (far right), a firm must engage its managers, operators, and engineers in improving its internal production processes in addition to in designing and making better products, as well as engaging its suppliers in continuous improvement through tighter supplier integration (far left):

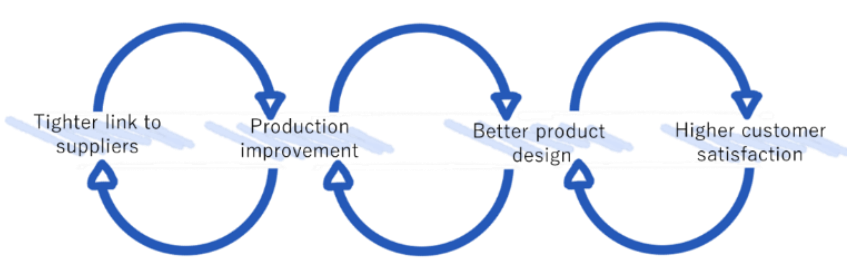

Figure 4 The Lean Strategy (adapted from Ballé et al., 2019b)

Better product design as a critical part of the lean transformation process in the ETO supply chain was an emergent discovery and learning point at both case companies, and is consistent with Lawson et al. (2015) which suggests that involving suppliers in new product development (NPD) can generate substantial improvements in operational performance (Wieteska, 2020) and supports the proposition that collaborative strategic improvement should not only focus on improving operations, but must also reach upstream to the product development process, what Sakai (2018) suggests is the true source of value creation in manufacturing.

To summarize, Ballé et al. (2017) suggest that the aim of a lean strategy is not to achieve operational excellence through adoption of lean tools and techniques per se, but rather to learn to solve the right problems and avoid wasteful solutions by:

\footnotetext{
${ }^{1}$ SweCo was up until April 1st, 2019 an independent company but was then acquired by the same corporate group that NorCo belongs to. The lean program presented in the case of NorCo, above, had thus not been implemented at SweCo at the time of this study.
} 
- Establishing flow in order to surface and discover real problems.

- Challenging ourselves to face these real problems by admitting the limits of our current knowledge.

- Relying on lean thinking to frame these problems and knowledge gaps as learning projects, that everyone can relate to in their daily work; and finally,

- Forming and assimilating new solutions / actionable knowledge that emerges from the new culture of problem solving and continuous improvement at all levels.

What we discovered in analysing the Lean and Learn approach adopted in both case studies is that when lean thinking is systematically combined with organizational learning in the context of ETO supply chains, it creates the conditions for the development of much greater supply chain capabilities in terms of time, cost, and quality. Referring to our initial theoretical framework (Figure 3), for example, the adoption of A3 management as a lean best practice fostered cross-functional (organizational) learning and led to improved supply chain capabilities, which materialized as a quality improvement on a scale of $30 \%$ in the case of NorCo. This was also true regarding the adoption of the Kanban solution - a lean best practice which provided the firm with a learning frame to discover problems and learning opportunities as they emerged - and subsequently led to $50 \%$ improvement in the delivery capabilities of the firm. We therefore suggest that organizations set aside more time for discovering learning opportunities rather than focussing purely on delivery performance alone.

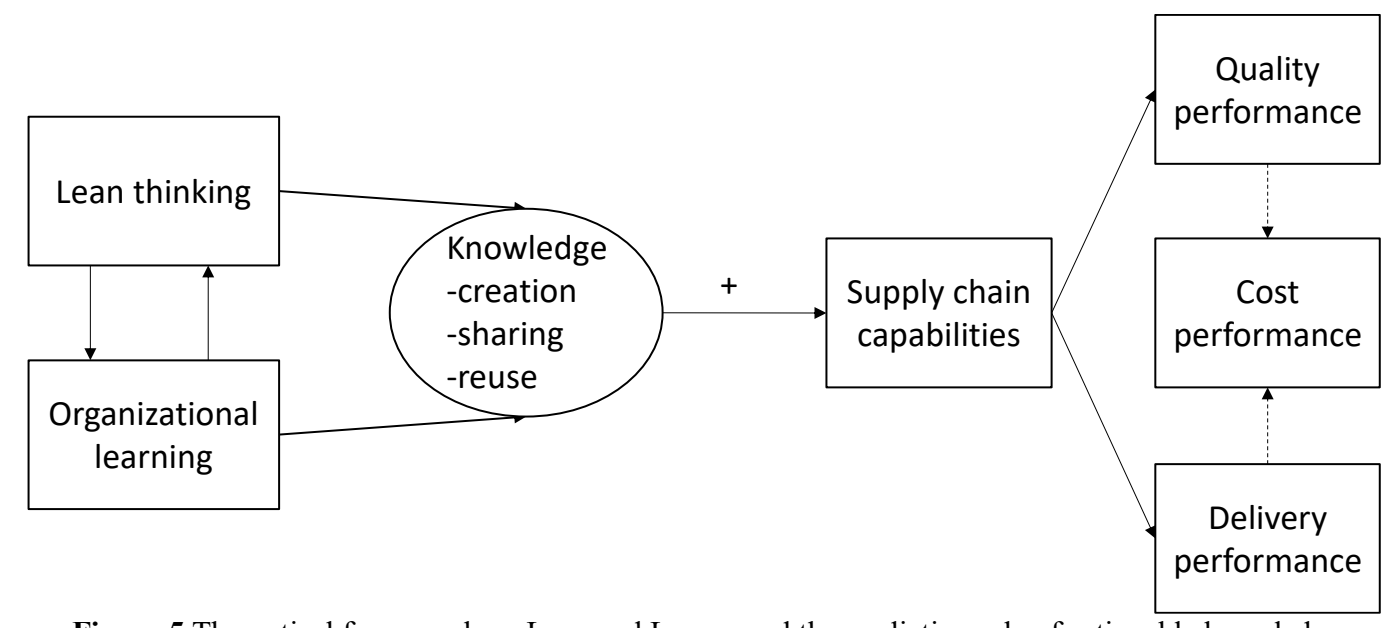

Figure 5 Theoretical framework - «Lean and Learn» and the mediating role of actionable knowledge

A critical finding that surfaced during the investigation is that this relationship $($ Lean + Learn $=$ supply chain capability improvement) seemed highly dependent on the further capabilities of the organization to harness, share, and re-apply the knowledge created from the "Lean and Learn" process, hence introducing a mediating effect in knowledge creation, knowledge sharing and knowledge reuse. This suggests that if an organization is better able to capture and communicate new and emergent actionable knowledge (within and across the firms in the supply chain), the likelihood of achieving improved supply chain capabilities will be amplified and demands a revision to our theoretical framework (see Figure 5). We also suggest that digitalization may have a key role to play in mediating the effect of the Lean and Learn approach on supply chain capabilities, as digital technologies which allow for greater vertical and horizontal integration might provide specific means for yokoten within and across organizations. We saw indications of this phenomenon specifically in the NorCo case - where online web-platforms were used to share the results of best practice implementations, as well as new actionable knowledge, both within and across sites.

Additionally, though we did not discover a direct relationship to cost performance, based on the case studies we argue that both increased quality performance and increased delivery performance positively influence the cost performance of the ETO supply chain (also reflected in Figure 5). This is also in line with the findings by Hallgren et al. (2011), which suggests that improvements in cost performance are often the result of improvements in other operational measures.

\section{CONCLUSION}

This paper set out to investigate the potential of a Lean and Learn approach in enhancing the capability of ETO supply chains. The aim was to develop, present, and test a theoretical framework which can be further used to promote the development of successful continuous improvement cultures in ETO manufacturers.

Drawing on important insights from both lean thinking and organizational learning, we present the "Lean and Learn" framework for enhancing an organization's supply chain performance - measured in terms of quality, cost, and delivery metrics. The results from our multiple case study analysis revealed that the Lean and Learn approach, while mediated by the ability to harness, share, and redeploy new, actionable knowledge, has a positive effect on quality and delivery performance, which in turn has a positive effect on cost performance. For example, improving quality performance reduces production costs (i.e., cost-of-poorquality), and improving on-time-delivery reduces the occurrence of expensive fines for late deliveries in projectbased supply chains.

We suggest that an ETO organization can be an individual firm, but more importantly, should rather entail the whole supply chain to include important inter-firm 
learning and collaboration (Mukhtar and Azhar, 2020). In reflection, we conclude that when lean is framed in the context of a discovery and learning process rather than as a strict set of 'best practices' to adopt (or indeed adapt), organizations appear to gain enhanced supply chain capabilities.

With regard to implications for practice, we suggest that organizations must switch the mindset that "we are different - lean does not work here" to more of a discovery and learning mindset, where all opportunities to learn and improve are taken. We also make implications for research in identifying a need to recognize that there are repetitive and concurrent elements even in ETO products and supply chains that can enhance intra- and inter-firm learning. Thus, further research should consider the Lean and Learn approach in other ETO supply chains as well as in other industry types. As SweCo was acquired by NorCo in 2019, it would also be interesting to evaluate how interfirm learning takes place (or not) in the event of mergers and acquisitions, and which mechanisms might be at play during such takeovers. We also identify opportunities to investigate the role of digitalization in capturing and sharing new actionable knowledge within and across organizations.

\section{ACKNOWLEDGEMENTS}

This research has been supported by The Whispering Game project, focusing on efficient communication for responsive supply chains. The project is funded and supported by the Swedish Knowledge Foundation (KKstiftelsen), the SPARK environment at Jönköping University, and the participating companies.

\section{REFERENCES}

Alieva, J., and von Haartman, R. (2020). Digital Muda-The New Form of Waste by Industry 4.0. Operations and Supply Chain Management: An International Journal 13(3), 267 - 278.

Backlund, F., and Sundqvist, E. (2018). Continuous improvement: challenges for the project-based organization. International Journal of Quality \& Reliability Management, 35(7), 13061320.

Ballé, M., Chaize, J., and Jones, D. (2019a). Lean as a learning system: What do organizations need to do to get the transformational benefits from Toyota's method? Development and Learning in Organizations: An International Journal.

Ballé, M., Chartier, N., Coignet, P., Olivencia, S., Powell, D., and Reke, E. (2019b). The Lean Sensei. Go. See. Challenge. Boston, MA: Lean Enterprise Institute, Inc.

Ballé, M., Jones, D., Chaize, J., and Fiume, O. (2017). The Lean Strategy: using lean to create competitive advantage, unleash innovation, and deliver sustainable growth: McGraw Hill Professional.

Bechky, B. A. (2003). Sharing meaning across occupational communities: The transformation of understanding on a production floor. Organization Science, 14(3), 312-330.

Bäckstrand, J. (2012). A Method for Customer-driven Purchasing: Aligning Supplier interaction and Customer-driven manufacturing. School of Engineering, Jönköping University, Jönköping.

Bäckstrand, J., and Engström, A. (2016). The lead time tree as a boundary object for developmental learning and improved conditions for purchasers. Paper presented at the $5^{\text {th }}$ World conference on Production and Operations Management P\&OM, Havanna, Cuba, 6-10/9 2016.
Bäckstrand, J., and Engström, A. (2017). Overcoming Contradictions through Cross-functional Integration in an ETO-context. Paper presented at the 77th Annual Meeting of the Academy of Management, Atlanta, Georgia, United States, August 4-8, 2017.

Chakraborty, S., and Gonzalez, J. (2018). An integrated lean supply chain framework for US Hospitals. Operations and Supply Chain Management: An International Journal, 11(2), 98109.

Crossan, M. M., Lane, H. W., and White, R. E. (1999). An organizational learning framework: From intuition to institution. Academy of Management Review, 24(3), 522-537.

Elfving, J., Tommelein, I. D., and Ballard, G. (2002). Reducing lead time for electrical switchgear. Paper presented at the Proceedings of the 10th Annual Conference International Group in Lean Construction (IGLC 10), Gramado, Brazil

Ellström, P.-E. (2010). Practice-based innovation: a learning perspective. Journal of Workplace Learning, 22(1/2), 27-40.

Engström, A., and Käkelä, N. (2019). Early steps in learning about organizational learning in customization settings: A communication perspective. The Learning Organization, 26(1), 27-43.

Ferdows, K., and De Meyer, A. (1990). Lasting Improvements in Manufacturing Performance: In search of a New Theory. Journal of Operations Management, 9(2), 168-184.

Fine, C. H., and Hax, A. C. (1985). Manufacturing Strategy: A Methodology and an Illustration. Interfaces, 15(6), 28-46.

Gosling, J., and Naim, M. M. (2009). Engineer-to-order supply chain management: A literature review and research agenda International Journal of Production Economics, 122(2), 741754.

Gustavsson, M. (2007). The potential for learning in industrial work. Journal of Workplace Learning, 19(7), 453-463.

Hallgren, M., Olhager, J., and Schroeder, R. G. (2011). A hybrid model of competitive capabilities. International Journal of Operations \& Production Management, 31(5), 511-526.

Hansen, A. V., and Madsen, S. (2019). Theorizing in Organization Studies: Edward Elgar Publishing.

Hoekstra, S., and Romme, J. (Eds.). (1992). Integrated Logistics Structures: Developing Customer Oriented Goods Flow (1 $1^{\text {st }}$ English ed.). New York, NY: Industrial Press.

Irani, S. A. (2020). Job Shop Lean: An Industrial Engineering Approach to Implementing Lean in High-Mix Low-Volume Production Systems: CRC Press.

Jensen, C. A. (2017). Staged competition as a driver of construction innovation. Procedia Engineering, 196, 872-879.

Jonsson Egeman, M. (2019). Adapting the lead time tree model to include immaterial activities : Extending the lead time tree model to enable mapping, efficiency evaluation and waste identification in order fulfillment processes: Tekniska Högskolan, Högskolan i Jönköping, JTH, Produktionsutveckling.

Khan, H., and Wisner, J. D. (2019). Supply chain integration, learning, and agility: Effects on performance. Operations and Supply Chain Management: An International Journal 12(1), $14-23$

Käkelä, N., and Bäckstrand, J. (2019). Sharing knowledge for customization: a triadic perspective. Paper presented at the 26th International Annual EurOMA Conference, Helsinki, Finland, 17-19 June.

Lacoste, S., and Johnsen, R. E. (2015). Supplier-customer relationships: A case study of power dynamics. Journal of Purchasing and Supply Management, 21(4), 229-240.

Lawson, B., Krause, D., and Potter, A. (2015). Improving supplier new product development performance: the role of supplier development. Journal of Product Innovation Management, 32(5), 777-792. 
Liker, J. K. (2004). The Toyota way: 14 management principles from the world's greatest manufacturer. New York; London: McGraw-Hill.

March, J. G. (1991). Exploration and exploitation in organizational learning. Organization Science, 2(1), 71-87.

Mason-Jones, R., Naylor, B., and Towill, D. R. (2000). Engineering the Leagile Supply Chain. International Journal of Agile Management Systems, 2(1), 54-61.

Mello, M. H., Gosling, J., Naim, M. M., Strandhagen, J. O., and Brett, P. O. (2017). Improving coordination in an engineerto-order supply chain using a soft systems approach. Production Planning \& Control, 28(2), 89-107.

Mello, M. H., and Strandhagen, J. O. (2011). Supply chain management in the shipbuilding industry: challenges and perspectives. Proceedings of the Institution of Mechanical Engineers, Part M: Journal of Engineering for the Maritime Environment, 225(3), 261-270.

Mello, M. H., Strandhagen, J. O., and Alfnes, E. (2015). Analyzing the factors affecting coordination in engineer-to-order supply chain. International Journal of Operations \& Production Management, 35(7), 1005-1031.

Miller, J. (2011). How to Do Yokoten. Retrieved 7th January 2021, from

https://blog.gembaacademy.com/2011/03/21/how to do yo koten/.

Mukhtar, U., and Azhar, T. (2020). Inter-functional Coordination to Co-create Value Within Integrated Value Chains for Competitive Supply Chain. Operations and Supply Chain Management: An International Journal, 13(1), 11-22.

Nakane, J. (1986). Manufacturing futures survey in Japan: A comparative survey 1983-1986. System Science Institute, Waseda University, Tokyo.

Naylor, B., Naim, M. M., and Berry, D. (1999). Leagility: Integrating the lean and agile manufacturing paradigms in the total supply chain. International Journal of Production Economics, 62, 107-118.

Netland, T. H., and Powell, D. J. (2017). A Lean World. In Netland, T. H. \& Powell, D. J. (Eds.), The Routledge Companion to Lean Management (pp. 465-473). New York: Routledge.

Nevis, E., DiBella, A., and Gould, J. (1995). Understanding organizations as learning systems. Sloan Management Review, 36(Winter), 73-85.

Nonaka, I. (1994). A dynamic theory of organizational knowledge creation. Organization Science, 5(1), 14-37.
O'Reilly, C. A., and Tushman, M. L. (2004). The ambidextrous organization. Harvard Business Review, 82(4), 74.

Powell, D., and van der Stoel, A. (2017). Lean Engineer-to-Order Manufacturing. In The Routledge Companion to Lean Management: Routledge New York.

Powell, D. J., and Coughlan, P. (2020a). Corporate Lean Programs: Practical Insights and Implications for Learning and Continuous Improvement. Procedia CIRP, 93(2020), 820825 .

Powell, D. J., and Coughlan, P. (2020b). Rethinking lean supplier development as a learning system. International Journal of Operations \& Production Management, 40(7/8), 921-943.

Sakai, T. (2018). The Secret Behind the Success of Toyota. London: Amazon.

Sánchez, J. H., Sánchez, Y. H., Collado-Ruiz, D., and CebriánTarrasón, D. (2013). Knowledge creating and sharing corporate culture framework. Procedia-Social and Behavioral Sciences, 74, 388-397.

Skinner, W. (1969). Manufacturing: Missing Link in Corporate Strategy. Harvard Business Review, 47(3), 136-145.

Wells, P., and Nieuwenhuis, P. (2017). Operationalizing Deep Structural Sustainability in Business: Longitudinal Immersion as Extensive Engaged Scholarship. British Journal of Management, 28(1), 45-63.

Wheelwright, S. C. (1978). Reflecting Corporate Strategy in Manufacturing Decisions. Business Horizons, 21(1), 57-66.

Wieteska, G. (2020). The Impact of Supplier Involvement in Product Development on Supply Chain Risks and Supply Chain Resilience. Operations and Supply Chain Management: An International Journal, 13(4), 359-374.

Wikner, J., and Rudberg, M. (2005). Integrating production and engineering perspectives on the customer order decoupling point. International Journal of Operations \& Production Management, 25(7), 623-641.

Womack, J. P., Jones, D. T., and Roos, D. (1990). The Machine that Changed the World ( $1^{\text {st }}$ ed.). New York: HarperCollins Publishers

Wortmann, J. C., Muntslag, D. R., and Timmermans, P. J. M. (Eds.). (1997). Customer-driven manufacturing. London, UK: Chapman \& Hall.

Yin, R. K. (2018). Case Study Research and Applications: Design and Methods ( $6^{\text {th }}$ ed.). Los Angeles, CA: SAGE.

Dr. Jenny Bäckstrand is associate professor in Supply chain and Operations Management at the School of Engineering at Jönköping University, Sweden. She presented her thesis - A Method for Customer-driven Purchasing - Aligning Supplier Interaction and Customer-driven Manufacturing as the first Doctor of Philosophy in Science at Jönköping University in 2012. She has published articles on various topics related to purchasing and customized products in a triadic setting as well as engaged research methods. Her current research interests include university-industry interaction and information sharing, specifically in SME companies and ETO-contexts.

Dr. Daryl Powell is Research Manager at SINTEF Manufacturing in Norway and Adjunct Professor at the Norwegian University of Science and Technology (NTNU). He also holds a Visiting Professor position at the University of Bergamo in Italy. Powell has over 15 years of experience from working with Lean Production as both a practitioner in industry and as an academic researcher. He has an M.Sc. in Lean Manufacturing from the University of Wales (UK) and a Ph.D. in Lean Production Planning and Control from NTNU. 